\title{
The recruitment agent in internationalised higher education: Commercial broker and cultural mediator
}

\author{
Dr. Anna Magyar and Professor Anna Robinson-Pant \\ School of Education and Lifelong Learning \\ University of East Anglia \\ Norwich NR4 7TJ, UK
}

\begin{abstract}
The internationalisation and marketisation of higher education has resulted in UK universities' increasing reliance on recruitment agents to boost international student numbers. This places agents and agencies in a position of considerable influence with regards to the educational choices that students make. These institutional and individual relationships have been investigated from a marketing perspective, contributing knowledge about the influence of recruitment agents on student decisionmaking. However, this approach has limitations with regard to understanding the impact of agents on an international student's subsequent experience in UK higher education. The paper suggests that theoretical work on mobility, migration and ethnographies of communication, including the geopolitics of text production, can provide useful lenses for analysing how agents help international students navigate the journey into and through UK higher education. The notion of 'cultural mediator' is introduced to analyse the role played by agents alongside that of commercial broker. We argue that future research shaped by these alternative theoretical perspectives may help to bridge the apparent gap in understanding between those working in international offices and those involved in teaching in an internationalised university.
\end{abstract}

\section{Biographical details}

Anna Robinson-Pant is Professor of Education at the School of Education and Lifelong Learning, University of East Anglia, and holds the UNESCO Chair for Adult Literacy and Learning for Social Transformation. She was based for around ten years in Nepal, working with a range of NGOs as researcher and adult educator. Her research focuses on literacy, gender and development and the internationalisation of higher education.

Anna Magyar is Research Associate in the School of Education and Lifelong Learning, University of East Anglia. Her research has focused on student writing, English for research purposes and internationalisation, in the context of the geopolitics of academic publishing. She facilitates an international writing-mentoring programme for new research writers in the South. 


\section{The recruitment agent in internationalised higher education: Commercial broker and cultural mediator}

\section{Introduction}

According to the Times Higher Education, 'About one in three international students in the UK is thought to be introduced to their university by an agent, and combined institutional spend on commission payments topped $£ 89$ million in 2013-14' $(25 / 2 / 2016)$. Within the current marketised model of higher education in the UK, it is not surprising that an economic rationale for internationalisation dominates (Maringe et al 2013) and that agents are seen as a key instrument for recruitment of international students (Raimo et al 2014, Observatory 2014). In the context of New Zealand, Collins (2012: 157) observed that agents 'filled a niche created by the withdrawal of state regulation from student mobility and educational provision in the 1990s'. Today, the UK faces a similar situation - just as it appears too late to debate whether the marketisation of higher education (HE) is a 'good thing', we also need to recognise that agents are an important element of the current HE landscape.

Most studies on recruitment agents in higher education are framed around the remit of HE international offices ${ }^{1}$, focusing on the agents' role in relation to recruitment and admissions. Concepts from business studies (agency theory, consumer behaviour and market orientation) largely inform the research questions and analysis. As a result, though we know about what happens before the student arrives in their overseas university in terms of their interaction with an agent, there is a lack of knowledge about how these new trajectories affect the student's subsequent academic experiences. This is partly because the focus has been on recruitment and admission ${ }^{2}$. But it is also because the theoretical framing of such studies has been informed by questions around student decision- making from a marketing perspective. In addition, research has rarely been conducted into the micro-level relationships between students and recruitment agents, probably for sensitive commercial and ethical reasons. This paper sets out to propose alternative theoretical frameworks which help conceptualise the role that agents play beyond that of commercial brokers and to consider instead the ways in which agents mediate the student's expectations of the university and more specifically, of the programme they attend.

As academics concerned about the impact of marketisation on teaching and learning in our own university, we see the need for alternative theoretical frameworks to the current instrumental approach to internationalisation promoted in many UK universities. Furthermore, in the increasingly commercialised higher education sector, as Hallak and Poisson (2005: 14) argue, a gap is opening up between the 'conflicting priorities of academics and managers'. This paper seeks to bridge this gap, in the belief that a better understanding of the relationship between agents and

\footnotetext{
${ }^{1}$ We are using the generic term 'International Office' though recognise that some universities do not have a separate department dealing with international recruitment or international relations. These functions are sometimes mainstreamed and can be found under broader Student Services.

${ }^{2}$ Although i-Graduate Barometer does survey international students 'from application to graduation', the nature of the survey means that it focuses on experiential outcomes rather than a micro-analysis of the processes and relationships that make up that experience (see: https://www.igraduate.org/services/international-student-barometer/).
} 
students will be of value to all those who have responsibility for teaching, planning and assessing learning.

\section{Methodology}

This article draws on two projects conducted in the UK from 2012-15: one with international students about their experiences of transition into postgraduate courses (Magyar and Robinson-Pant, 2014) and a scoping study for Society for Research in Higher Education (SRHE) on the role of recruitment agents in the internationalisation of higher education. In this sense, the design has been an iterative one in which both a review of the literature and of research informed by different theoretical perspectives played a central role.

It was through conducting an action-orientated research study with 22 international students that the multiple roles played by agents in guiding these students on their journey to UK higher education emerged. Using the student interview data about their interaction with agents before coming to the UK, we then designed a scoping study which focused on the role of agents in relation to student experience. Our aim was to explore possible directions for a future larger research project, through testing out alternative theoretical frameworks which might guide research questions and analysis and extend the scope of previous research in this area.

The major instrument for the scoping study was a comprehensive literature review focusing on the changing role and construction of agents in HE, including their relationship with educational providers and national governments. In order to engage with different theoretical perspectives on agents, internationalisation and mobility, we reviewed literature from a wider range of disciplines, including business studies, education, geography, psychology and applied linguistics. A small-scale empirical study was developed as a way of extending and interrogating our theoretical analysis, particularly to explore the implications of these lenses for policy and practice.

The research activities consisted of: observation of a university briefing session for recruitment agents visiting the UK from 19 agencies in 13 countries; documentary analysis of their agency websites; Skype interviews with eight agents; and interviews with three senior members of staff in a university International Office (in order to explore their roles, expectations and practices with respect to recruitment agents and to prepare a policy brief ${ }^{3}$ ). The data was analysed to identify emerging themes and interrogated through the theoretical lenses outlined later in section 5. Within this article, we draw on interview data and documentary analysis to develop a more 'situated' contextual account of the processes and roles associated with recruitment agents in UK universities (section 3). However, the empirical data is used mainly in the latter part of the article to explore how the theoretical lenses presented might offer new insights into agent practice and student experience. Given the parameters of a scoping study (as outlined above), we decided it would be more appropriate to use the data in this way, rather than writing a conventional research article which presents the 'findings and analysis' in a discrete section.

\footnotetext{
${ }^{3}$ See SRHE website for final scoping project report and policy brief: https://www.srhe.ac.uk/downloads/Robinson-Pant_BriefingPaper.pdf
} 


\section{Setting the scene: the rise of recruitment agents in higher education}

The term 'agent' in this paper refers to the individual, and 'agency' to the organisation which employs agents in the sending country.

Raimo et al's (2014:5) definition of agent activity within higher education (as given on the GOV.UK website) was particularly relevant to our study:

- Help to sell goods abroad

- Act on the principal's behalf by introducing him/her to overseas customers

- Give information and contacts for overseas markets

- Identify opportunities

- Cut costs of setting up overseas offices

In Australia and New Zealand, agents have been used since at least 1996 and ten years later, around $47 \%$ of international students had been recruited by agents (Mazzarol and Hosie, 2006). Canada has had least involvement with agents and it is only recently that the ban on American colleges using commissioned agents has been lifted (ICEF, 2014). In the UK, a major shift took place with the launch of the Prime Minister's Initiative 1 by Tony Blair in 1999 - this was a key government strategy to generate new income for UK universities through increasing international student recruitment. From this time on, HEIs began to work more closely with agents, seeing them as crucial to helping meet the new higher targets for international student recruitment (Krasocki, 2002). As Knight (2014) points out in her historical analysis of HEI policy, this 'commercial and competitiveness model' of internationalisation replaced the earlier development cooperative framework and partnership model.

Agents can be positioned as both 'the symptom and the effect' of commercialisation in HE (Hulme et al., 2013: 12), raising the question as to whether they serve to support or to direct student mobility. Hulme et al (ibid) warn that 'There is a danger that achievement of recruitment targets via agent activity may run ahead of thoughtful and theoretically informed internationalisation of the university curriculum'. Their reflection that this approach to internationalisation marginalizes academics and puts managers/administrators in the 'steering seat' (ibid) was particularly relevant to our study. In the case study university, we found a similar gap between academics and International Office staff, as well as a focus on recruitment rather than curriculum development within internationalisation policy documents.

A survey of 27000 first year international students revealed that $32 \%$ of those in UK HEIs had used agents, with a higher percentage at the undergraduate level (35\%) as compared to $\mathrm{PhD}$ students (12\%) (Observatory 2014: 31). Through our analysis of agency websites, we learned that agencies differed greatly in terms of governance structures and scope of services offered. Some large agencies have branches in a range of countries and others act as a 'go between', linking specific agents to individual institutions. The largest agencies provide practical services such as health insurance, travel insurance, visa processing, airport pick-up and accommodation, as well as more direct support for academic admissions such as application guidance, career counselling, interview practice, course advice and local job placement.

For instance, a Brazilian agency established fifty years ago that had only recently begun to offer counselling/advisory services to students wishing to attend university abroad, explained that they had only recently branched out from their main business 
of providing language courses abroad: 'We realised that students who participate in high school programmes come back wanting to continue with this experience - they already have language and experience - and this is our main target audience'. By contrast, an agent based in Pakistan dealt only with placing students in HE institutions. Many of these services are provided free to the student applicant since the recruiting HEI pays $10-15 \%$ of the student tuition fee to the agent as commission on conversion of an offer into a place on a course. However, the Observatory's (2014) report found that $75 \%$ of agents charged the student client as well. In our interviews, some agents justified this additional fee through saying that it was to make sure that the applicant was 'serious' and that in certain countries clients believed that they would get a better service if they paid.

Agents are attractive to UK HEIs because they speak local languages, can liaise with the student in person and have relevant networks in the country concerned. Many agents are former international students themselves and some set up small familybased small enterprises on their return home (see examples from Australia in Baas, 2007). An international office respondent in a UK university explained how they work together with agents to ensure more efficient communication:

'The norm now is that agents apply on behalf of the student - the student just gives the agent all the information and they also receive the emails and forward them to the students - mostly they are very good at this and translate the university's messages to the student (From interview).

Relationships between international offices and agents have become more formalised now, involving probationary periods, contracts and training requirements. Whereas previously universities would have appointed their own agents, now the majority of agents work independently and will represent a suite of universities. Raimo et al (2014: 14) reported from interviews with 57 colleagues in twenty HEIs that criteria for selection of new agents included 'morals and ethics, sensible and high quality service and a professional looking website'. In our scoping interviews, an international office respondent put a similar emphasis on these elements, explaining the rigorous selection and monitoring of agents in our case study university: 'If a member of staff wishes to nominate a new agent, staff have to write a brief report about them and follow up references and then there is a probationary period, along with anti-bribery policy and the British Council best practice guidelines.'

\section{Policy initiatives and institutional practices}

At the national and international level, there have been various policy initiatives to register, control and accredit agencies. In Australia, the responsibility is placed clearly with educational providers who have to register to The Commonwealth Register of Institutions and Courses for Overseas Students (CRICOS), managed by the Australian Government. They then have to demonstrate compliance with fifteen 'standards' of practice, which include the use of education agents (Australian Education International, 2014). In 2012, the first international initiative to address recruitment was launched. Called the London Statement ${ }^{4}$, the emphasis was on the agents'

\footnotetext{
${ }^{4}$ London Statement is shorthand for Statement of Principles for the Ethical Recruitment of International Students by Education Agents and Consultants. http://www.britishcouncil.org/organisation/press/landmark-international-code-ethics-education-agents
} 
accountability to students, rather than on university practice and responsibilities. Referred to as an 'ethical framework', the statement came out of a series of roundtables, the first held in 2010, by US, Canada, UK, Australia, New Zealand and Ireland. Critics of the London Statement point out, however, that the initiative provides no incentive to agents to comply with the code of conduct. In 2013, the British Council set up a register of those agents who had signed up to the code and undergone its training programme. It should be noted that the accreditation is for the individual agent, not for the agency to which they belong [from British Council briefing session notes, 2014]. Recently, the UK Government Department for Business, Innovation and Skills conducted a review of universities' use of recruitment agencies following concerns that they could be 'accomplices in immigration offences' (Havergal, 2016).

From this account, we can see that the role of agents and the structure of agencies have evolved in response to student demands, which are in turn influenced by the changing HE international marketplace. Within UK HEIs, it is the International Office that is intimately involved in developing and shaping the institution's relationship with agents - through written contracts, monitoring mechanisms and training. Of particular relevance to our investigation into student experience from the perspective of their prior interaction with agents, were our findings in the case study university that evaluation of agent performance (and payment of commission) stopped the moment the student entered UK higher education. There was, for example, no followup information or feedback given by course directors to the International Office (or agents) in terms of how students later performed in their degrees or even drop-out rates. This illustrates the gap (referred to earlier) between institutional knowledge on recruitment and on teaching/learning processes/outcomes. Academics only came into the picture when they provided information for recruitment purposes or attended recruitment fairs. It was surprising to us as academics that training events for agents appeared to focus on giving information about institutions, life in the UK and visa requirements - rather than providing any in-depth training about how to interact with and support clients in sourcing information about the specific courses offered by the institution or writing their applications. For instance, in our previous project interviews, students had discussed issues around translation and collaborative writing of statements with their agents. Yet these points did not seem to be openly addressed in training sessions held for agents.

Through interviews with International Office staff we became aware of tensions and contradictions facing those working within the international student recruitment business. Whereas ethical concerns about agents' practice were openly voiced and reflected in codes such as the London Statement, there was also a recognised lack of transparency amongst UK HEIs regarding total commission paid and agency relationships. Although universities increasingly emphasised the importance of written contracts and monitoring documentation, this was accompanied by much informal oral interaction and negotiation with agents. These apparent contradictions in HEI practice and values could be seen in relation to wider debates about how communicative practices (including teaching and learning) within higher education are changing due to increasing commercialisation and demands for greater accountability when students pay high fees. See for example, Robinson-Pant and Street's (2012) research into how the relationship between PhD supervisor and 
student in a UK university was being altered through a new requirement to document supervision interactions through formal minutes of meetings.

Thus the increasingly significant role of recruitment agents within higher education has both led to and is supporting a more instrumental approach to internationalisation. In our scoping research, we found that the International Office had developed close relationships with agents in order to monitor their activities, explore new markets and ensure increased international student recruitment rates. This perspective on recruitment agents as solely commercial actors is reflected in the research literature in this area, which comes largely from business theory perspectives and tends to frame them through a marketing lens, as we explore in the next section.

\section{Agents in higher education: the limitations of a marketing lens.}

Although some researchers have called for the eradication of recruitment agents, particularly in the US (see Reisberg and Altbach 2011), the majority of articles that we reviewed did not engage with polarised debates for or against agents. Starting from the assumption that agents are here to stay (see Brabner and Galbraith 2013), they set out to enhance understanding of how agents operate in the current HE market. Several researchers used consumer behaviour theory to analyse students' decision making about HEI destinations (see Chen 2008, Cubillo et al 2006, Simoes and Soares 2010). For instance, Pimpa's (2003) research with Thai students revealed that agents had a greater influence than peers. Hagedorn and Zhang (2011) found that among the services Chinese students and their parents expected from an agent was advice in choosing the destination country and institution.

This body of research has provided some evidence (largely quantitative survey data) on how agents, as compared to other factors, influence student decision-making. However, the methodology adopted by most of these studies provides no in-depth insights into the actual process of decision-making, such as how the applicant engages with specific social networks (friends, family, acquaintances who have been abroad). In this sense, there are limitations about applying theories around consumer behaviour to 'buying' education. In a report for the British Council on agents, Raimo et al (2014:6) caution that it needs to be remembered that a university degree 'is not just a commodity': 'it is not like buying a fridge that money alone can secure'.

The relationship between agents and HEIs has also been analysed through applying marketing theory, including the marketing orientation framework (Ross et al 2013) and agency theory (O'Connell 2012). Adopting agency theory, Huang, Raimo and Humfrey (2014) outlined two key assumptions: that both parties (agent and principal) will be motivated by self-interest and that agents 'will only selectively disclose information to the principal' (ibid: 3 ). Their article highlights some concerns around applying agency theory to this field - for instance, the finding that some HEI respondents are unsure that the agents had even read the contracts they are sent. For us, this again pointed to the need to understand more about how agents, HEI staff and students interact around written and spoken texts.

Research informed by marketing theory can provide insights into the ways in which the agent's role is evolving in the context of a more economised relationship between student and university, as well as highlight ethical concerns about quality being 
compromised through 'mis-selling' and 'misbehaviour' of agents (Brabner and Galbraith 2013). However, though this body of research told us much about the agent's impact on student recruitment, it appeared to exclude research questions exploring the nature of the student-agent interaction and led to a narrow focus on instrumental outcomes (in terms of recrutment) and control mechanisms.

Therefore, rather than focusing only on the agent as a commercial actor, we were interested to find a way of conceptualising the agent's mediating role between students and university, and across cultures - from an educational and intercultural learnng perspective. For this reason, we turned to research on mobility, migration and ethnographies of communication to provide a framework for investigating agents' roles and relationships with students.

\section{Agents in higher education: exploring alternative theoretical lenses}

\section{i) The new mobilities paradigm}

Brooks and Waters (2011) discuss the emergence of a 'new mobilities paradigm' in the social sciences which can help to theorise the mobility of international students. Their research illuminates the multiple agencies and identities negotiated by international students as they move between places and offers a critique of internationalisation as 'a highly positive process' (ibid; 135). Rather than only looking at students' experience at home or abroad, they propose that researchers need to focus instead on students' 'power to move from a to b' and the resources (such as the agent) that enable or disable mobility. The 'new mobilities' body of research is valuable in opening up the connections between higher education markets, migration and globalised economies more generally and has clear relevance to the analysis of recruitment agents' role. Meanwhile, the notion of mobility as a 'collective endeavour where movement of one individual takes the work of multiple people' (Friedmand and Miller-Idriss 2014: 153) could contribute to an analysis of the network of resources facilitating student movement across continents.

Often the connection between migration and studying abroad are deliberately obscured - as Baas' (2007) case study of 'special purpose' recruitment agencies working in India for Australian private colleges revealed. Both student applicants and agents were aware that the purpose of pursuing international higher education was to obtain Permanent Residence (PR) in Australia - and HEIs were responding through setting up courses strongly linked to employment (described as 'PR factories'). However, there was a conspicuous silence around permanent migration in recruitment activities. This research illuminates what happens when education is regarded as a 'product' that can be bought and sold. Taking a migration lens on HE internationalisation has also helped to problematise terms like 'value', which change meaning as educational institutions enter into an 'economised relationship' with students and agents (Hulme et al, 2013: 1).

Considering the wider role of agents in migratory processes, Collins (2012: 136) suggests that whereas the literature has characterised such intermediaries as 'either part of a solely profit-oriented migration industry or the social networks of migrants themselves', the educational agents actually 'bridge both worlds' and have an 'inbetween status'. His analysis of how international education contributes to the 
organisation of mobility and processes of migration demonstrates the value of viewing agents 'as the connection between increasingly formalised regulatory systems, market dynamics of migration and the social lives of international migrants' (ibid: 137). Of particular relevance to questions around how agents interact with students is Collins' analysis of a Korean education agent who formerly studied in the US and UK. He concluded that agents' 'own experience as an international student not only informs the advice they provide to students but also affects their relationships with students' (ibid: 154). By exploring the ways in which agents mediated and drew on different networks and cultural resources, Collins presents a more holistic perspective on agents and on the organisation of mobility - 'the ways in which different actors - the state, agents, education providers, students and their families contribute to the infrastructure of migration' (ibid: 136).

Taking these theoretical lenses from migration and mobility studies, we found that we could examine the role of agents not only as commercial brokers in relation to higher education markets but as contributing to global economic processes of migration too. Methodologically, this research pointed to ways of investigating the agent's mediating role and the processes involved in moving and communicating between countries.

Rather than framing research questions around the effectiveness, risks and benefits of agents, this lens helps to shift the research focus onto the complex relationship between education, mobility and social/cultural capital, including language.

\section{ii) Ethnographies of communication}

The relationships between agents, students and HEIs can be seen as constructed around written and oral texts, including university and agency websites, email correspondence, contracts, phone calls, briefing sessions and Skype meetings. As discussed earlier, from a marketing perspective, some of these events and documents have been analysed in terms of mechanisms for power and control (see Huang et al 2014). An academic literacies framework, which emphasizes the ideological dimension in academic practices (Lea and Street 1998, Lillis and Scott 2007) provides a different perspective through which to analyse the agent's role as literacy mediator (in terms of the agent interpreting, constructing and translating text both for the UK HEI and for the student applicant). In earlier research (Magyar and Robinson-Pant (2011), we adopted a similar perspective to investigate how academic relationships between international doctoral students and their supervisors were shaped by their differing ideologies of academic reading and writing.

Theoretical tools around authorial voice and writer identity (Ivanic 2005) provided an important starting point in our scoping study for exploring how agents, students and academics involved read and constructed texts. For instance, rather than starting from the assumption that the individual student applicant wrote the application form alone, we instead took the position that writing is collaborative and analysed how the agent was involved in this process - possibly scribing oral conversations, translating from another language into English, editing and proofreading or giving feedback as a teacher might. An agent in Brazil explained to us that he 'sent back' applications to the student if they were not good enough.

From our investigation into the field of recruitment agencies, we noticed that the term 'culture' remained unproblematised in discussions about international recruitment and 
agents - with both agents and HEI international offices sharing a dichotomised and essentialised view of the 'home' culture as contrasted with 'English' culture. This critique of the static polarised model of home/international is similar to that posed by the 'new mobility paradigm' discussed above. Challenging an essentialist notion of 'culture', intercultural communication researchers (see Holliday 1999, 2011) propose ways of exploring 'how and when culture plays an active role in shaping and influencing our meaning making endeavours' (Sarangi 1995: 26). Taking this perspective on both the ideas of 'culture' held by HEIs and by agents could provide valuable insights into how both HEIs and agents construct 'English values' (Raimo et al, 2014 - respondent), influencing how the student will negotiate multiple policy and academic cultures through their journey to UK higher education. Our discussions with agents revealed that practices and values in the student's 'home' culture are changing rapidly (such as noting an increasing dependence on parents and agents) and that a more dynamic model for theorising about cultural and social change could be helpful.

Although the theoretical approaches outlined above had not been adopted in the research we reviewed on recruitment agents, Blommaert's (2004) research with a Burundese asylum seeker in Belgium (who is asked to produce 'proof about his country' (ibid: 654) for the authorities) suggested that micro-level analysis of texts might contribute greater understanding into agents' role as 'literacy mediators' beween the UK university and the student. Blommaert (2004: 660) examines a 'clash of two different economies, one guiding the production of the [application] documents and the other guiding their uptake'. His notion of the text being produced 'in a transnational context: a Burundese subject producing text in Belgium addressed to Belgian legal officials' (ibid) has clear relevance to the situation of international students. This kind of analysis in relation to agents' roles in supporting applications could help us to build up a more complex understanding of what actually happens when texts move 'from the peripheries of the world system to its centres' (ibid: 661). When reading application forms, there is a tendency to try to identify the 'true' voice of the student - as Blommaert questioned in the context of the Burundian papers he analysed, 'How do we get to the fullness of voice-as-knowledge in such documents?' We need to recognise that authorship may be collective and that texts may be read, written and interpreted very differently when writing styles and conventions 'get transferred from one particular social, cultural, communicative and linguistic environment to another' (ibid: 644).

Developing a theoretical framework around the geopolitics of text production and ethnographies of communication thus seemed to offer an approach for investigating in more depth the recruitment agent's role in the globalised economy of higher education. In our analysis of the literature and empirical data in the scoping study, we used this broader perspective on texts as multi-modal (including visual, spoken, digital and written texts) and as 'artefacts of globalisation processes' (ibid: 654) to move away from the conventional assumption of a hierarchy between written and oral texts.

In the following section, we draw on these alternative lenses around literacy, culture and identity to look more closely at the interaction between student applicants and agents. We draw on data from our scoping study to illustrate how these alternative theoretical perspectives could point to new research questions and approaches. We aim to broaden the research investigation from agents as commercial actors to 
consider their roles in mediating language, culture and academic literacies between the student applicant and UK university.

\section{Agents as cultural mediators and mentors: research perspectives}

Looking at our interview data through the lens of literacy and cultural mediation, it emerged that agents had not only helped to provide information about possible universities and how to fill in the visa application, but had also given feedback on the applicant's personal statement and advice on what to highlight.The agents were providing information about specific courses or expected English language test scores that would guide a student's decision making. But more importantly, they were explaining how the required texts (application forms, personal statements) might be read and interpreted in a different cultural and linguistic context.

From our Skype interviews with agents (all of whom were dealing directly with individual clients), we were aware of the multiple and shifting identities that agents adopted when they interacted with student applicants. Several agents had recently returned from postgraduate studies in the UK and emphasised that they drew on their 'insider knowledge' as former international students to advise applicants about the realities of studying abroad. For instance, Mariko, an agent in Japan, explained how she challenged her clients' idea that 'it is really easy to study abroad and we have to encourage them to study hard'. She shared her own educational experiences from a year she had spent in the UK and commented that 'for them, this sounds more realistic'. Similarly, Mohammed, an agent in Pakistan, when asked about training for the role, explained: 'I used my own experience which I faced while I applied for my studies abroad'.

Sara, a Taiwanese agent, described how she drew on her previous work as a social worker, particularly her counselling skills: 'Some clients are picky, fussy and unreasonable, but I could handle them easily with my social worker skills'. She showed a strong commitment to her clients, emphasising the need to 'carefully listen to clients (students and their parents) and making sure what they need'. Although these agents were working in a competitive market place and their livelihood depended on 'selling' education, they nevertheless talked about their role in similar terms to that of a teacher and mentor. As Yuyin, an agent in Vietnam, emphasised: 'I love jobs relating to education, this is an interesting job. It is one kind of business, but it is 'education'. I love dealing with students, they keep me young and happy'.

The interviews gave an insight into the ways in which agents interacted with clients around different texts - including university websites, application forms and university requirements. Su, an agent in Thailand, outlined how she worked with around $15-20$ clients a week. She had taken a Masters in Marketing Communications in the UK and moved into the recruitment agency sector in Thailand after informally advising friends and family about study abroad: 'It was like a hobby of mine'. Collins (2012: 136) suggests that whereas the literature has characterised such intermediaries as 'either part of a solely profit-oriented migration industry or the social networks of migrants themselves, agents can actually 'bridge both worlds' and have 'an in between status'. It was evident that Su drew on her firsthand experience and understanding of UK universities to take on the role of a 'critical friend' in supporting clients to develop their application: 
Su uses Google to get all the initial information about universities that might be helpful for a customer. She helps the client with the application, giving advice on ways in which they should change it to meet the university requirements, what documents they should change and gives them help with the visa application. She gives guidelines for the personal statement, listens to their previous history and gives them advice on what they need to include, like adding key information about the course. She keeps asking them to revise it until it is right for the application [from interview notes]

In Su's account, we can begin to see the role that she plays as literacy mediator (in terms of interpreting the UK university requirements and advising on the student's text), clearly linking with the theoretical conceptualisation of literacy as a collaborative rather than individualised social practice (Ivanic 2005).

Agents commented on the changing international HE environment in which they worked and how this influenced their roles. Several agents commented on the differences between when they themselves had applied for university in the UK (sometimes over a decade ago) and their clients' current expectations. Su identified a greater culture of dependency: 'the kids these days are too much dependent on us. Sometimes they don't even read the emails from the university and expect the agent to do everything. I tell them "you are going to study abroad, you need to read all the information yourself". It is totally different from my time. I had to do things for myself, the counsellor did not help that much'. She also mentioned the increasing role that parents had in the relationship with the agent: 'my parents never came with me to the counsellor. Now it is the parents who are deciding and they come with the customer'. Seen through the lens of the 'new mobilities paradigm' (Brooks and Waters 2011), her account supports the notion of mobility as a 'collective endeavour' (Friedman and Miller-Idriss, 2014: 153), where the student and agent are interacting within a network of relationships and resources.

The growing international higher education market has also led to a proliferation of institutions and of information available. Kenichi, an agent in Japan, reflected on how little he knew about education in the UK before he chose his own course, as there was not much on the internet at that time. He observed that 'now applicants are faced with too much information and they need to study it carefully' and he saw a key role of the agent as helping them navigate through this information. In the increasingly competitive HE market, Sara (in Taiwan) was concerned about her clients' potentially unethical practices and she observed that: 'Many clients tend to shop agencies and submit more than 15 applications. I hope that I could educate my clients a healthy concept about pursuing international higher education. I hope that all agents put clients' interests prior to their profits: this is 'Education' not 'Business only'. We can see that these agents were describing the mentoring role that they played in relation to clients - whether encouraging them to adopt an ethical approach to the application process or helping them to filter relevant information. However, this was not always the case and some agents preferred to deliver a service rather than act as mentors or teachers. For instance, Luis, a Brazilian agent described how 'students come with heaps of questions, which counsellors find the answers to on the website'.

This interview data shows that agents interact with their clients in wide-ranging ways, and that the commercialisation of HE significantly shapes these relationships. These 
initial findings suggest that in the context of an increasingly globalised higher education, a theoretical lens informed by ethnographies of communication and the geopolitics of text production offers new insights into the role of agents as cultural and literacy mediators. Framing future research in this way could point to new research questions that explore identity, voice and power with regard to the university application process, as well as focusing research attention onto the micro level practices of agents and prospective students. A future study might, for instance, investigate the research question: How do the communicative practices that agents and clients engage in at the application stage influence students' expectations and later experiences of overseas university education? A starting assumption could be that agents 'model' types of interaction that students then anticipate in learning and teaching situations in a UK university.

\section{Implications and recommendations for policy and practice in higher education internationalisation}

We have argued that learners' expectations are not only shaped by commercialisation but by the application process and the agent's role in that process. By considering how agents might collaborate in producing and mediating student applications, this analysis also raises important policy-related questions for those working in HEIs. In terms of bridging the gap between academic and recruitment dimensions, Blommaert's (2004) research points to the educational dimension of 'reading' texts from and in other places - emphasising that this differs not only across genres but also across communities and contexts. One response to our initial study findings might be to introduce academic course directors to the field of intercultural communication research (Holliday, 2011) - particularly intercultural rhetoric which analyses varying assumptions about the reader and writer relationship and rhetorical conventions within different writing traditions (Connor, 2004). This might encourage academic admissions officers to consider how applicants' texts could be read and interpreted in another cultural context.

With regard to developing more rigorous admissions processes, this approach raises questions such as how can we take better account of the often invisible third party? What purposes does the personal statement serve at present? Although many UK universities do not require an interview for most undergraduate and postgraduate taught courses, there could be an argument for complementing written applications with informal oral interviews that focus on the personal statement.

In terms of internationalisation that goes beyond the instrumental and enhancing the international student experience, HEIs need to develop a more integrated approach across the institution to agent monitoring and evaluation. One step might be to attempt to disaggregate data on admissions and later performance (for instance, at the end of the first year of a course) according to whether students had been recruited via an agency. In many UK universities, International Offices do not receive any feedback from academics on the outcomes in terms of the quality of students recruited. Likewise, when academics become aware of new students' unrealistic expectations of courses or required skills, there may not be a direct channel for giving feedback to those involved in recruitment. 
Finally, critical investigation into the role of education agents in shaping student expectations is important not just to bridge the gap between administrators and academics or between recruitment and academic experience, but also for generating insights into the ways that $\mathrm{HE}$ is being transformed due to commercialisation. Our research into agents as relatively recent but crucial actors in this landscape provided us as academics with an alternative perspective on the wider relationships, purpose and values currently being promoted by UK HEIs and points to wider implications for enhancing student experience, admissions processes and internationalisation strategies.

\section{Acknowledgements}

This work was supported by a SRHE scoping project grant. We would like to thank all the agents and staff in the case study university who participated in interviews. We would like to acknowledge the advice and support of our colleagues in the UEA International Office, particularly Karen Blackney, who helped in the initial stages of the project and later with developing approaches to dissemination. Above all, we would like to thank Dr. Janette Ryan for her role as mentor on the SRHE project and her insightful comments on an earlier draft of this paper.

\section{List of references}

Australian Education International, Education Services for Overseas Students, downloaded 14/11/2014 from: https://www.aei.gov.au/RegulatoryInformation/Education-Services-for-Overseas-Students-ESOS-LegislativeFramework/National-Code/nationalcodepartd/Pages/ExplanatoryguideD4.aspx

Baas, M. (2007) The Language of Migration: the Education Industry versus the Migration Industry. People and Place, Vol. 15, No. 2, pp $49-60$

Blommaert, J. (2004) Writing as a problem: African grassroots writing, economies of literacy, and globalization, Language in Society 33, 643-671

Brabner, R. and G. Galbraith (2013) Using international recruitment agents: risks and regulation? Stimulus Paper, Leadership Foundation for Higher Education, July 2013

Brooks, R. and J. Waters (2011) Student mobilities, migration and the internationalisation of higher education, Basingstoke: Palgrave Macmillan

Chen, L. (2008) Internationalizatiohn or international marketing? Two frameworks for understanding international students' choice of Canadian universities, Jounral of Marketing for Higher Education, 18: 1, pp 1-33

Collins, F. (2012) Organizing student mobility: education agents and student migration to New Zealand, Pacific Affairs, Vol. 85, No. 1, pp 135 - 158

Connor, U. (2004). Intercultural rhetoric: beyond texts, Journal of English for Academic Purposes 3, 291-304. 
Cubillo, J., Sanchez, J.,Cervino, J. (2006) International students' decision making process, International Journal of Educational Management, Vol. 20 Issue 2, pp.101 115

De Vita, G. and P. Case (2003) Rethinking the internationalisation agenda in UK higher education. Journal of Further and Higher Education, 27(4), 383-398

Friedman, J. and C. Miller-Idriss (2014) Gateways and guest homes: how US area studies centers serve as arbiters of study mobility, in Streitwieser, B. (ed.)

Internationalisation of Higher Education and Global Mobility, Oxford: Symposium Books

Hagedorn, L. and L.Y. Zhang (2011) The use of agents in recruiting Chinese undergraduates, Journal of Studies in International Education, 15 (2), pp 186 - 202

Havergal, C. (2016) 'Universities' use of recruitment agents under scrutiny', Times Higher Education, February 25 ${ }^{\text {th }}, 2016$

Holliday, A. (1999) Small Cultures, Applied Linguistics, 20, 237-264

Holliday, A. (2011) Intercultural Communication and Ideology, London: Sage Publications

Huang, I., Raimo, V. and C. Humfrey (2014) Power and control: managing agents for international student recruitment in higher education, Studies in Higher Education. Published online 23/10/14, DOI: 10.1080/03075079.2014.968543

Hulme, M., Thomson, A., Hulme, R. and Doughty, G. (2013) Trading Places: The role of agents in international student recruitment from Africa. Journal of Further and Higher Education. Published online 09 May 2013, DOI:

10.1080.0309877X.2013.778965.

ICEF (2014) 'United States Poised For More Active Student Recruitment', http://monitor.icef.com/2014/06/united-states-poised-for-more-active-studentrecruitment, $30^{\text {th }}$ June 2014

Ivanic, R. (2005) The discoursal construction of writer identity, in Beach, R. et al (eds) Multidisciplinary Perspectives on Literacy Research, Cresskill: Hampton Press

Knight, J. (2014) Three generations of crossborder Higher Education: new developments, issues and challenges, in Streitwieser, B. (ed.) Internationalisation of Higher Education and Global Mobility, Oxford: Symposium Books

Krasocki, J. (2002) Education UK: Developing the UK's International Agent Network. Promotions and Partnerships (ECS), London: The British Council.

Lea, M. and B. Street (1998) Student writing and staff feedback in higher education: an academic literacies approach, Studies in Higher Education, 23(2), 157-172 
Lillis, T. and M. Scott (2007) Defining academic literacies research: issues of epistemology, ideology and strategy, Journal of Applied Linguistics, 4.1, 5-32

Magyar, A. and A. Robinson-Pant (2011), Internationalising doctoral research: developing theoretical perspectives on practice, Teachers and Teaching, 17(6), 663677

Magyar, A. and A. Robinson-Pant (2014) Preparing for academic study in a second language: how can we improve the experience of engagement of international Masters students? University of East Anglia Teaching Fellowship Report (unpublished)

Maringe, F., Foskett, N. and S. Woodfield (2013) Emerging internationalisation models in an uneven global terrain: findings from a global survey, Compare, Vol. 43, No. 1, pp 9-36

Mazzarol, T and Hosie, P (2006). Exporting Australian higher education. Quality Assurance in Education. Vol.4, No 1, pp

The Observatory on Borderless Higher Education (2014) The Agent Question: Insights from students, universities and agents, September 2014

Pimpa, N (2003) The Influence of Peers and Student Recruitment Agencies on Thai Students' Choices of International Education Journal of Studies in International Education. vol. 7 no. 2, 178-192

Raimo, V., Humfrey, C. and I. Huang (2014) Managing international student recruitment agents: Approaches, benefits and challenges, British Council, $16^{\text {th }}$ October 2014

Reisberg, L. and P. Altbach (2011) The ambiguities of working with third-party recruiters, International Higher Education, No. 63, Spring 2011, pp 3 - 6, The Boston College Center for International Higher Education

Robinson-Pant, A. and B. Street (2013) Students and tutors' understanding of 'new' academic literacy practices', in Castello (eds) University writing: selves and texts in academic societies, Emerald Press, pp 71-92

Sarangi, S. (1995) Culture. In J. Verschueren (Ed), Handbook of pragmatics, Amsterdam: John Benjamins

Simoes, C. and A. Soares (2010) Applying to higher education: information sources and choice factors, Studies in Higher Education, Vol. 35, No. 4, pp 371-389 